\title{
Overexpression of the TGF $\beta$-regulated Zinc Finger Encoding Gene, TIEG, Induces Apoptosis in Pancreatic Epithelial Cells
}

\author{
Issei Tachibana, ${ }^{\star}$ Mami Imoto, ${ }^{*}$ Philip N. Adjei, ${ }^{\ddagger}$ Gregory J. Gores, ${ }^{\ddagger}$ Malayannan Subramaniam, ${ }^{\S}$ Thomas C. Spelsberg, ${ }^{\S}$ \\ and Raul Urrutia*§ \\ *Gastroenterology Research Unit, Saint Marys Hospital, Mayo Clinic; ${ }^{\ddagger}$ Center for Basic Research in Digestive Diseases, and ${ }^{\S}$ Department \\ of Biochemistry and Molecular Biology, Mayo Clinic, Rochester, Minnesota 55905
}

\begin{abstract}
Members of the TGF $\beta$ family of peptides exert antiproliferative effects and induce apoptosis in epithelial cell populations. In the exocrine pancreas, these peptides not only regulate normal cell growth, but alterations in these pathways have been associated with neoplastic transformation. Therefore, the identification of molecules that regulate exocrine pancreatic cell proliferation and apoptotic cell death in response to TGF $\beta$ peptides is necessary for a better understanding of normal morphogenesis as well as carcinogenesis of the pancreas. In this study, we have characterized the expression and function in exocrine pancreatic epithelial cells of the TGF $\beta$-inducible early gene (TIEG), a Krüppel-like zinc finger transcription factor encoding gene previously isolated from mesodermally derived osteoblastic cells. We demonstrate that this gene is expressed in both acinar and ductular epithelial cell populations from the exocrine pancreas. In addition, we show that the expression of TIEG is regulated by TGF $\beta 1$ as an early response gene in pancreatic epithelial cell lines. Moreover, overexpression of TIEG in the TGF $\beta$-sensitive epithelial cell line PANC1 is sufficient to induce apoptosis. Together, these results support a role for TIEG in linking TGF $\beta$-mediated signaling cascades to the regulation of pancreatic epithelial cell growth. (J. Clin. Invest. 1997. 99:2365-2374.) Key words: transforming growth factor- $\beta$ - zinc finger $\bullet$ transcription factor $\bullet$ apoptosis $\bullet$ pancreas
\end{abstract}

\section{Introduction}

The number of cells in a particular organ is maintained through a delicate balance between cell proliferation and cell death. Therefore, a precise regulation of cell division and apoptosis is required for normal morphogenesis and, not surprisingly, alterations in these processes can lead to neoplastic transformation. Studies from several laboratories have provided a mechanistic model that indicates that cell proliferation results from an interplay between cell signaling and transcriptional regulation $(1,2)$. According to this model, mitogenic growth factors and antiproliferative peptides transduce signals emanating from cell surface transmembrane receptors that recruit a distinct set of intracellular "signaling proteins." These proteins then act on nuclear transcription factors to ultimately

Address correspondence to Raul Urrutia, GI Research Unit, Saint Marys Hospital, Mayo Clinic, Rochester, MN 55905. Phone: 507-2847500; FAX: 507-255-6318; E-mail: urrur@mayo.edu

Received for publication 23 December 1996 and accepted in revised form 7 March 1997.

The Journal of Clinical Investigation

Volume 99, Number 10, May 1997, 2365-2374 modify the expression of genes responsible for cell proliferation. In many circumstances, moreover, cell death is also triggered by the activation of cell surface receptors and requires the participation of nuclear transcription factors (3).

Our final goal is to gain a better understanding of the molecular mechanisms involved in the regulation of cell proliferation and apoptotic cell death in exocrine ductular pancreatic cells since these cells are believed to be the origin of pancreatic cancer (4). Among the most important pathways that regulate the proliferation and/or death of exocrine pancreatic cells are those mediated by members of the TGF $\beta$ family of peptides. Recent studies have suggested an important role for these peptide growth factors in maintaining an appropriate balance between the number of exocrine and endocrine cells during pancreatic development (5). Interestingly, alterations in TGF $\beta$ mediated signaling cascades are often found in pancreatic diseases. For instance, an upregulation in the expression of several members of this family of peptide growth factors is found in chronic pancreatitis, and this alteration has been proposed to participate in the development of both the fibrosis and the parenchymal atrophy that are landmarks of this disease (6-11). This observation is further supported by the fact that transgenic animals overexpressing TGF $\beta 1$ develop pancreatic lesions compatible with chronic pancreatitis $(7,9)$. In addition, the levels of TGF $\beta$ peptides, TGF $\beta$ receptors, and the TGF $\beta$ associated tumor suppressor DPC4 gene have all been linked to the development of pancreatic cancer (12-14). Consequently, characterization of the molecular machinery involved in mediating the effects of TGF $\beta$ peptides in exocrine pancreatic cells will be very useful for understanding the cellular events underlying normal pancreatic morphogenesis and is relevant to pancreatic diseases such as pancreatitis and cancer.

We have been studying the participation of zinc finger transcription factors in the regulation of pancreatic cell proliferation by epidermal growth factor and gastrointestinal hormones (15-18). This family of transcription factor proteins has been demonstrated to be potent regulators of normal morphogenesis from insects to vertebrates and, when mutated, can give rise to neoplastic transformation. In kidney, for instance, WT1 is a regulator of cell proliferation during embryogenesis (19) and mutations in this gene are responsible for Wilms tumor (20). Therefore, the identification and functional characterization of zinc finger proteins that may link the activation of TGF $\beta$ peptides to the regulation of pancreatic cell growth will significantly expand our understanding of this phenomenon.

In this report, we have characterized the expression, TGF $\beta$ regulation, and function of the zinc finger transcription factor TGF $\beta$-inducible early gene (TIEG) ${ }^{1}$ in exocrine pancreatic

1. Abbreviations used in this paper: HA, hemagglutinin A epitope tag; TIEG, TGF $\beta$-inducible early gene; TUNEL, terminal deoxynucleotidyl transferase-mediated dUTP nick end labeling. 
cell populations. This gene was previously isolated from human osteoblastic cells as a TGF $\beta 1$-inducible transcript (21), but its functional role in epithelial cell populations remains poorly understood. Interestingly, TGF $\beta$ is a mitogenic peptide in mesenchymal cells, such as osteoblasts, while the peptide growth factor is antiproliferative in epithelial cells, such as pancreatic cell populations (22). Here, we report that TIEG is expressed in both acinar and ductular exocrine pancreatic cell populations and is regulated by TGF $\beta 1$ as an early response gene in exocrine pancreatic cell lines. More importantly, overexpression of TIEG is sufficient to induce apoptosis in these cells. Together, our results demonstrate that TIEG is a TGF $\beta$ regulated zinc finger protein in exocrine pancreatic cells and provide evidence for a role for TIEG in mediating the negative effects of TGF $\beta 1$ on pancreatic cell growth.

\section{Methods}

Cell culture. The rat pancreatic cell line AR42J (CRL1492) and the human pancreatic ductular cell lines PANC1 (CRL1468), MIAPaCa2 (CRL1420), BxPC3 (CRL1687), HS766T (HTB134), and Capan1 (HTB79) were obtained from American Type Culture Collection (Rockville, MD) and cultured under an atmosphere containing 5\% $\mathrm{CO}_{2}$ in DMEM (AR42J, PANC1, MIAPaCa2, and HS766T) or RPMI1640 (BxPC3 and Capan1) supplemented with 10\% FBS (GIBCO BRL, Gaithersburg, MD) and $100 \mathrm{U} / \mathrm{ml}$ penicillin/100 U/ml streptomycin (GIBCO BRL).

Library screening, sequencing, and Northern blot analysis. For the isolation of the rat TIEG cDNA, a rat pancreatic cDNA library (Stratagene Inc., La Jolla, CA) was screened under high stringency conditions using a full length human TIEG cDNA probe (21). A total of $10^{6}$ amplified recombinant plaques were screened using the human TIEG cDNA probe labeled to a specific activity of $2 \times 10^{8} \mathrm{cpm}$ per $\mu \mathrm{g}$ of DNA as previously described (23). Sequencing was performed using a thermocycler-based double-stranded DNA sequencing system (GIBCO BRL). The analyses of sequences and database comparisons were performed using MacVector (Eastman Kodak Co., Rochester, NY) and GCG (Madison, WI) DNA analysis softwares. Total RNA was prepared by the method of Chomczynski and Sacchi (24) and Northern blot analysis was performed as previously described (23) using $4 \mathrm{ng} / \mathrm{ml}$ of randomly primed ${ }^{32} \mathrm{P}$-labeled full length TIEG cDNA probe. For determining TIEG expression in response to TGF $\beta 1$, pancreatic cell lines were cultured in DMEM or RPMI-1640 containing $1 \%$ FBS for $24 \mathrm{~h}$. Subsequently, the media was changed to the same media with or without $5 \mathrm{ng} / \mathrm{ml}$ TGF 1 (Austral Biologicals, San Ramon, CA) for various times before RNA isolation. $1 \mu \mathrm{g} / \mathrm{ml} \mathrm{ac}-$ tinomycin D (Sigma Chemical Co., St. Louis, MO) or $10 \mu \mathrm{g} / \mathrm{ml}$ cycloheximide (Sigma Chemical Co.) were applied $30 \mathrm{~min}$ before, and together with, TGF $\beta 1$ for the early response experiments. Membranes were washed with a final stringency of $0.1 \times$ SSPE plus $0.1 \%$ SDS at $65^{\circ} \mathrm{C}$. Each experiment was performed at least two different times. For quantitative purposes, signals obtained for TIEG gene expression were normalized to the level of glyceraldehyde-3-phosphate dehydrogenase (GAPDH) mRNA or 18S rRNA after blot rehybridization as previously described $(21,23)$.

Western blot analysis and immunohistochemistry. For the detection of TIEG and the TGF $\beta$ types I and II receptor proteins by Western blot analysis, aliquots of pancreatic cell homogenates $(100 \mu \mathrm{g}$ total protein) were separated by SDS-PAGE (25) and transferred to nitrocellulose as previously described $(26,27)$. Protein concentration was determined by the BCA method (Pierce, Rockford, IL). The polyclonal antibodies against the TGF $\beta$ type I and II receptor were obtained from Santa Cruz Biotechnology, Inc. (Santa Cruz, CA). The anti-TIEG antiserum that recognizes an epitope spanning amino acids 134-154 (human) and 119-139 (rat) from TIEG was raised in rabbits against a synthetic peptide according to standard procedures (28).
Anti-TIEG IgG was immunopurified by affinity chromatography using the peptide conjugated to agarose (29). $1 \mu \mathrm{g}$ of an in vitro transcribed and translated human TIEG protein was used as a positive control. In vitro transcription and translation was performed using $1 \mu \mathrm{g}$ of full length human TIEG cDNA in Bluescript SK II (Stratagene Inc.) and $\mathrm{TNT}^{\circledR}$ Lysate (Promega Corp., Madison, WI) according to the manufacturer's specifications. Immunohistochemistry using the anti-TIEG antibody and an avidin-biotin immunoperoxidase detection system (Zymed Laboratories, Inc., South San Francisco, CA) was performed as previously described (27). Antigen retrieval was achieved by heating samples for $10 \mathrm{~min}$ in a microwave oven $(800 \mathrm{~W})$ in the presence of Antigen Retrieval ${ }^{\mathrm{TM}}$ Citra solution (BioGenex Labs., San Ramon, CA). As a control, preimmune serum was used.

Cell proliferation assay. A full length human TIEG cDNA was subcloned into the cytomegalovirus-based expression vector pMEXneo to generate pMEX-neo-TIEG. PANC1 cells were seeded in 100$\mathrm{mm}$ dishes, and transiently transfected with either of these two vectors using LipofectAMINE ${ }^{\mathrm{TM}}$ (GIBCO BRL) according to the manufacturer's directions. After $24 \mathrm{~h}$, transfected or untransfected PANC1 cells were plated in 96-well microtiter plates at a density of $0.5 \times 10^{4}$ cells per well in DMEM with $10 \%$ FBS. After $12 \mathrm{~h}$, the medium was changed to DMEM containing $1 \%$ FBS, and was subsequently changed every $24 \mathrm{~h}$. The number of cells at this time $(t=0)$ and at 24 and $72 \mathrm{~h}$ was determined using the colorimetric MTS assay (Promega Corp.). For determining transfection efficiency, PANC1 cells were transfected with a plasmid encoding $\beta$ galactosidase, harvested, and stained using the $\beta$-Gal Staining Kit (Invitrogen Corp., San Diego, CA) according to the manufacturer's instructions. The percentage of cells positive for $\beta$-gal was determined under a light microscope.

Apoptosis assays. pMEX-neo-TIEG-transfected, control vector (pMEX-neo)-transfected, or untransfected PANC1 cells were split onto coverslips or 100-mm dishes in DMEM with $10 \%$ FBS $24 \mathrm{~h}$ after transfection. After $12 \mathrm{~h}$, medium was changed to DMEM containing $1 \%$ FBS. To quantitate nuclear changes indicative of cell death by apoptosis, PANC1 cells were stained with the membrane-permeant fluorescent DNA binding dye, 4,6-diamidino-2-phenylindol $(5 \mu \mathrm{M})$, and viewed under a photomicroscope (Carl Zeiss, Inc., Thornwood, NY) at $250 \times$ using $360-380-\mathrm{nm}$ excitation and 515-565-nm emission filters as previously described (30-32). The nuclear changes in chromatin condensation/margination and nuclear fragmentation were used to identify apoptotic cells. At least 300 cells in four high power fields were counted, and apoptotic cells were expressed as a percentage of total cells. To confirm the results of the morphological assessment of apoptosis, we also analyzed the DNA for apoptotic laddering as previously described (30-32).

For determining apoptosis in individually transfected cells, we used the terminal deoxynucleotidyl transferase-mediated dUTP nick end labeling technique (TUNEL) and differential interference contrast microscopy. Cells were cotransfected with the pMEX-neo-TIEG and the marker plasmid pHook 2 lacZ (Invitrogen Corp.) encoding for the hemagglutinin A (HA) epitope that allows us to separate transfected from untransfected cells by immunofluorescence using the 12CA5 monoclonal antibody (Boehringer Mannheim Biochemicals, Indianapolis, IN) (33). Cells undergoing apoptosis were identified by the morphological criteria of nuclear fragmentation, nuclear margination, and organelle disorganization using differential interference contrast microscopy as previously described (34). DNA fragmentation was determined in situ by the TUNEL technique using the cell death detection system from Boehringer Mannheim Biochemicals according to the manufacturer's specifications.

\section{Results}

TIEG is expressed in exocrine pancreatic cells and encodes a member of a growing family of Sp1-like zinc finger proteins. TIEG is a TGF $\beta$-inducible zinc finger encoding gene recently identified from mesodermally derived human osteoblastic cells 


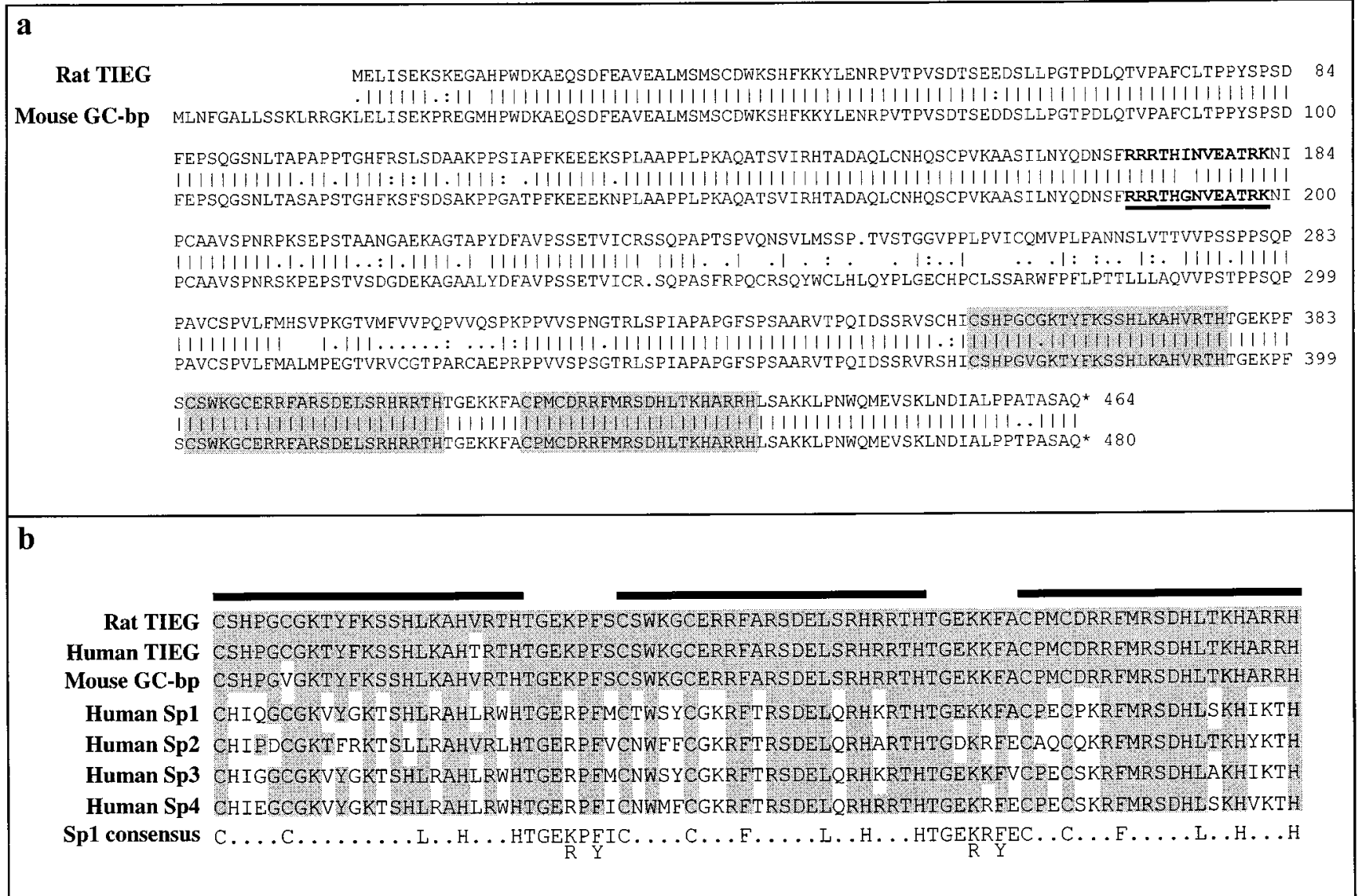

Figure 1. TIEG is a member of a growing family of Sp1-like zinc finger proteins. (a) Sequence alignment between the rat TIEG and the murine Sp1-like GC binding protein (S52306; Genbank/EMBL/DDBJ). Numbers to the right refer to amino acid residues. Comparisons were performed using the default settings of the GAP program (GCG). Stippled boxes indicate three zinc finger motifs. The putative nuclear localization signal is in bold and underlined. Note that the rat TIEG protein is $82.3 \%$ identical to the mouse GC binding protein throughout its entire sequence. $(b)$ Alignment of the zinc finger encoding region of the rat TIEG protein to the databank reveals high homology with the zinc finger DNA binding motif of the human Sp1, Sp2, Sp3, Sp4, human TIEG, and mouse Sp1-like GC binding protein. Alignments were obtained using the default settings of the BLAST alignment program (GCG). Stippled boxes indicate identical residues at that position. The solid lines indicate the three zinc finger motifs present in this family of proteins. Note that the zinc finger motifs of the rat TIEG are 98.8, 98.8, 66.7, 64.2, 67.9, and $66.7 \%$ identical to the zinc finger motifs of the human TIEG, mouse GC binding protein, and human Sp1, Sp2, Sp3, and Sp4 proteins, respectively, at the protein level.

by Subramaniam et al. using differential display PCR (21). In this study, with the goal of understanding the role of TIEG in epithelial cell populations, we have characterized the expression, TGF $\beta$ regulation, and function of this gene in exocrine pancreatic cell populations. Strong evidence for the expression of TIEG in pancreatic cell populations was first obtained through the cloning of this gene from a rat pancreas cDNA library. Using a cDNA probe against the human TIEG gene, we isolated several clones that together span the entire coding region of the rat homologue, which is identical to the human gene product (Fig. $1 \mathrm{a}$ ). Interestingly, comparison between these clones and sequences deposited in existing databanks demonstrate that TIEG belongs to a growing family of Sp1like zinc finger proteins. This subfamily of krüppel-like zinc finger transcription factors is composed of many members that display high homology within their DNA-binding motifs. Fig. $1 b$ shows that the zinc finger DNA-binding motifs of TIEG match the consensus for this family of proteins and are $>65 \%$ identi- cal to the structural and functional paradigm of this family, Sp1. In addition, TIEG is $>80 \%$ similar to another Sp1-like GC binding protein from mouse throughout its entire sequence (Fig. $1 a$ ).

We have subsequently analyzed the expression and localization of TIEG in rat and human exocrine pancreatic cell populations using Northern blot analysis and immunohistochemistry. The results shown in Fig. 2 demonstrate that TIEG is enriched in the rat pancreas and in six different exocrine pancreatic cell lines. In addition to pancreatic cell populations, TIEG is expressed in other adult rat tissues including heart, kidney, and lung, suggesting that the product of this gene may also participate in TGF $\beta$-mediated processes in these tissues. To determine which cell populations in the exocrine pancreas express TIEG, we performed immunohistochemistry in adult pancreas. For this purpose, we used an affinity-purified antiTIEG antibody that recognizes an epitope spanning amino acids 134-154 (human) and 119-139 (rat) of TIEG. This antibody 


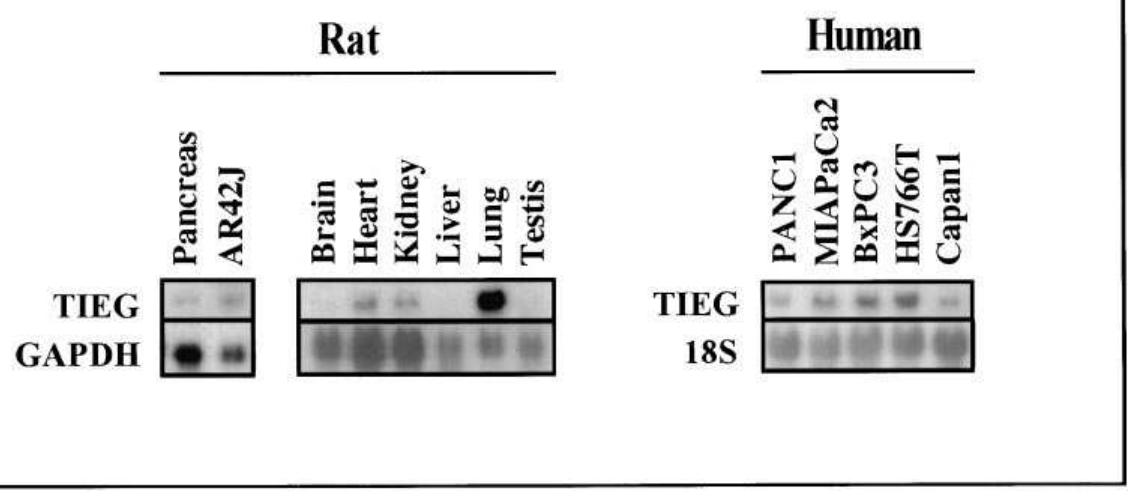

Figure 2. Expression of TIEG in adult rat tissues and exocrine pancreatic cell lines. Northern blot analysis was performed on RNA isolated from rat pancreas, brain, heart, kidney, liver, lung, and testis. In addition, the expression of TIEG was determined in the rat pancreatic cell line AR42J and the human cell lines PANC1, MIAPaCa2, BxPC3, HS766T, and Capan1. Rat samples were hybridized with a rat TIEG probe while the human samples were hybridized with the full length human TIEG cDNA. Control hybridization with the house keeping gene probes glyceraldehyde-3-phosphate dehydrogenase (rat) and $18 \mathrm{~S}$ (human) were used to normalize loading. Note that the TIEG mRNA is enriched in the adult rat pancreas and the six different pancreatic cell lines tested. In addition, this gene is also expressed in the heart, kidney, and lung. does not recognize other members of the SP1-like protein since the epitope used for the immunization is not present in any other member of this family. Fig. $3 a$ shows that this antibody specifically recognizes an in vitro translated human TIEG protein as well as a band of the same size corresponding to the TIEG protein from rat and human exocrine pancreatic cell lines that display the typical TGF $\beta$ inducibility of TIEG. Fig. $3 b$ demonstrates that, using this antibody, TIEG is localized to both the ductular and acinar cell populations in normal human exocrine pancreas. A similar staining pattern is detected in rat pancreas and control staining with preimmune serum is negative (data not shown). Together, these results clearly demonstrate that TIEG is an Sp1-like zinc finger encoding gene that is highly expressed in both rat and human exocrine pancreatic cell populations.
TIEG is an early response gene for TGFB1 in pancreatic cell lines. Because the expression of TIEG is rapidly regulated by TGF $\beta 1$ in mesenchymal cell populations (21), we investigated whether this gene is also a target for TGF 31 in pancreatic epithelial cell lines. TGF $\beta$ peptides signal through a heterodimeric receptor complex of TGF $\beta$ type I and II receptors (22). The expression of these receptors in the exocrine pancreatic cell lines, PANC1, MIAPaCa2, BxPC3, HS766T, and Capan1 was verified using Western blot analysis (Fig. $4 a$ ). These cell lines were subsequently treated with TGF 1 for $2 \mathrm{~h}$ and the expression of TIEG was examined by Northern blot analysis. Fig. $4 b$ shows that the expression of TIEG is upregulated within $2 \mathrm{~h}$ of TGF $\beta 1$ treatment in human pancreatic cell lines, which express both TGF $\beta$ types I and II receptors.

Because of this rapid induction and the functional impor-

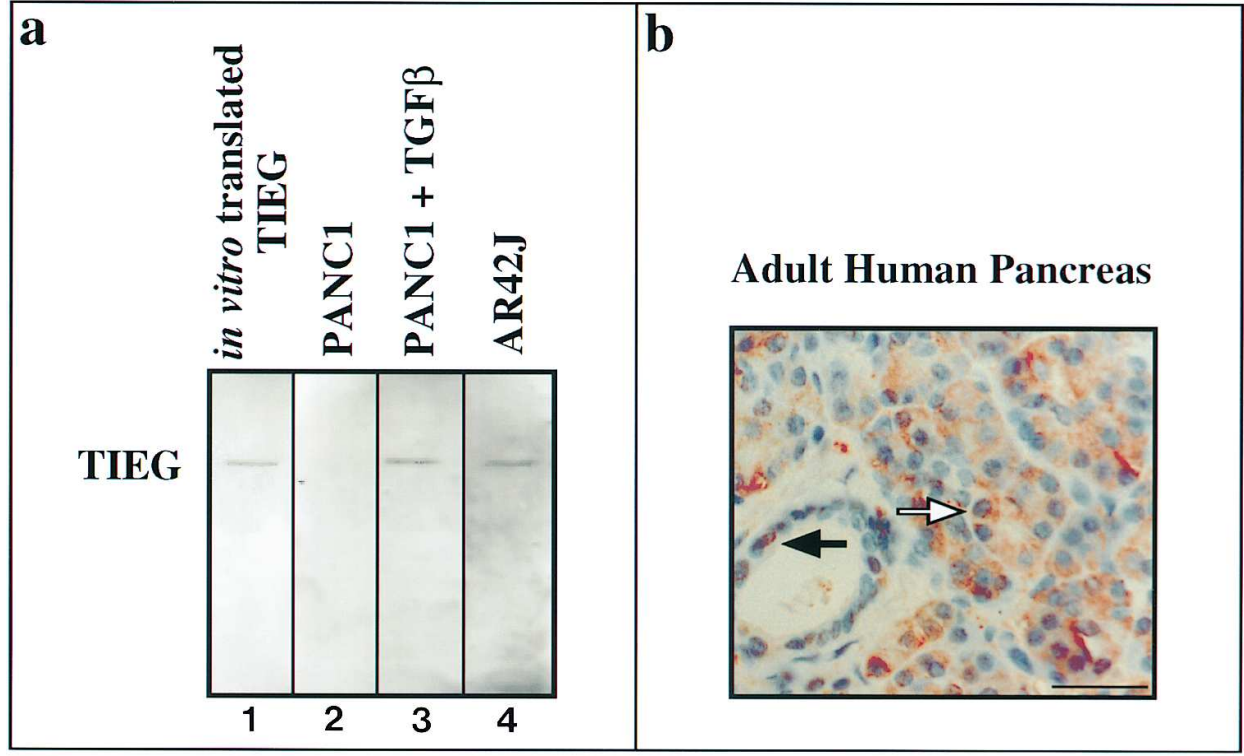

Figure 3. Expression and localization of TIEG in exocrine pancreatic cell populations. (a) Specific detection of TIEG in pancreatic cell populations as determined by Western blot analysis. Western blot was performed using an antibody that recognizes an epitope spanning amino acids 134-154 (human) and 119-139 (rat). The origin of the samples is indicated at the top of the panel. (lane 1) $1 \mu \mathrm{g}$ of an in vitro translated human TIEG protein, (lane 2) $75 \mu \mathrm{g}$ lysate from untreated human PANC1 cells, (lane 3) $75 \mu \mathrm{g}$ lysate from PANC1 cells after $2 \mathrm{~h}$ treatment with $5 \mathrm{ng} / \mathrm{ml}$ TGF $\beta 1$, (lane 4) $75 \mu \mathrm{g}$ lysate from rat AR42J exocrine pancreatic cells. Note that the antibody specifically recognizes a protein from both rat and human samples that comigrates with the in vitro translated TIEG protein. (b) Immunohistochemical localization of TIEG in normal adult human exocrine pancreas. The positive staining for TIEG is shown as a red precipitate (aminoethyl carbazole substrate) in acinar (white arrow) and ductular (black arrow) cells of the exocrine pancreas. Counterstaining was done with hematoxylin (blue). Control staining with preimmune serum was negative (not shown). Bar indicates $100 \mu \mathrm{m}$. 


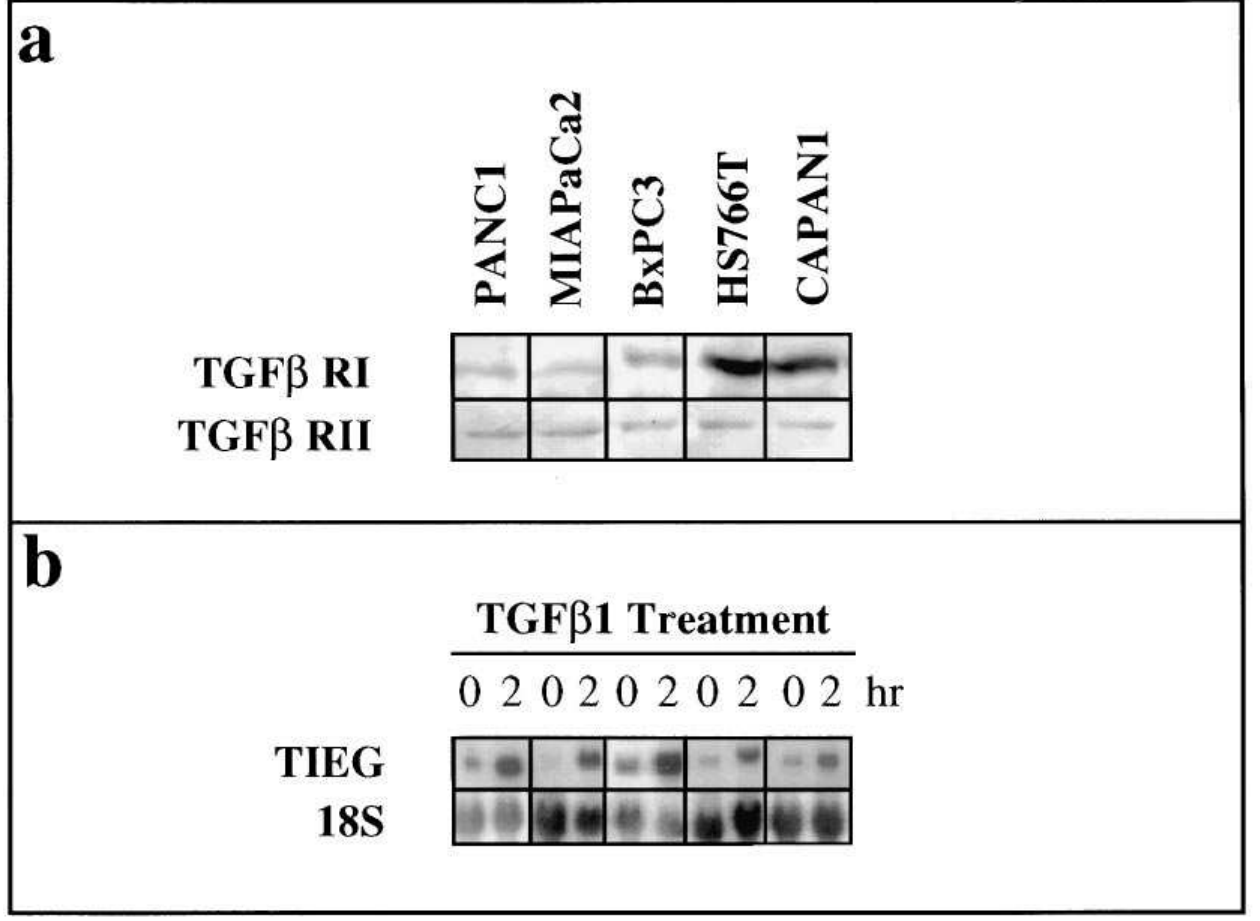

Figure 4. The expression of TIEG is regulated by TGF $\beta 1$ in pancreatic epithelial cell lines. The TGF $\beta$ inducible expression of TIEG was determined in the pancreatic epithelial cell lines PANC1, MIAPaCa2, BxPC3, HS766T, and Capan1. (a) Expression of the TGF $\beta$ type I and II receptors in pancreatic epithelial cell lines as determined by Western blot analysis. Approximately $100 \mu \mathrm{g}$ of each pancreatic epithelial cell lysate was separated by SDS-PAGE and transferred to nitrocellulose. Blots were probed with antibodies against the TGF $\beta$ type I and II receptors. The expression of both TGF $\beta$ receptors was detected in all the pancreatic cell lines tested. (b) The expression of TIEG is regulated by TGF $\beta 1$ in pancreatic epithelial cell lines. Each TGF $\beta$ receptor-positive pancreatic epithelial cell line was treated with $5 \mathrm{ng} / \mathrm{ml} \mathrm{TGF} \beta 1$ for $2 \mathrm{~h}$ before RNA extraction. Northern blot analysis was performed using $10 \mu \mathrm{g}$ total RNA. Note that the expression of TIEG was detected in all of the cell lines tested. In addition, the levels of TIEG mRNA are significantly upregulated in response to TGF $\beta 1$ treatment.

tance of early response genes in growth factor signaling pathways (26), we also tested whether the TGF $\beta 1$-mediated upregulation of TIEG mRNA levels is independent of protein synthesis. Fig. 5 shows that the TIEG upregulation by TGF $\beta 1$ in PANC1 cells occurs within $2 \mathrm{~h}$, even in the presence of the protein synthesis inhibitor, cycloheximide. In contrast, treatment with the transcriptional inhibitor, actinomycin D, abolishes this upregulation of TIEG mRNA levels. Therefore, these data demonstrate that TIEG is an early response target for TGF $\beta 1$ in pancreatic cell populations and that the effects

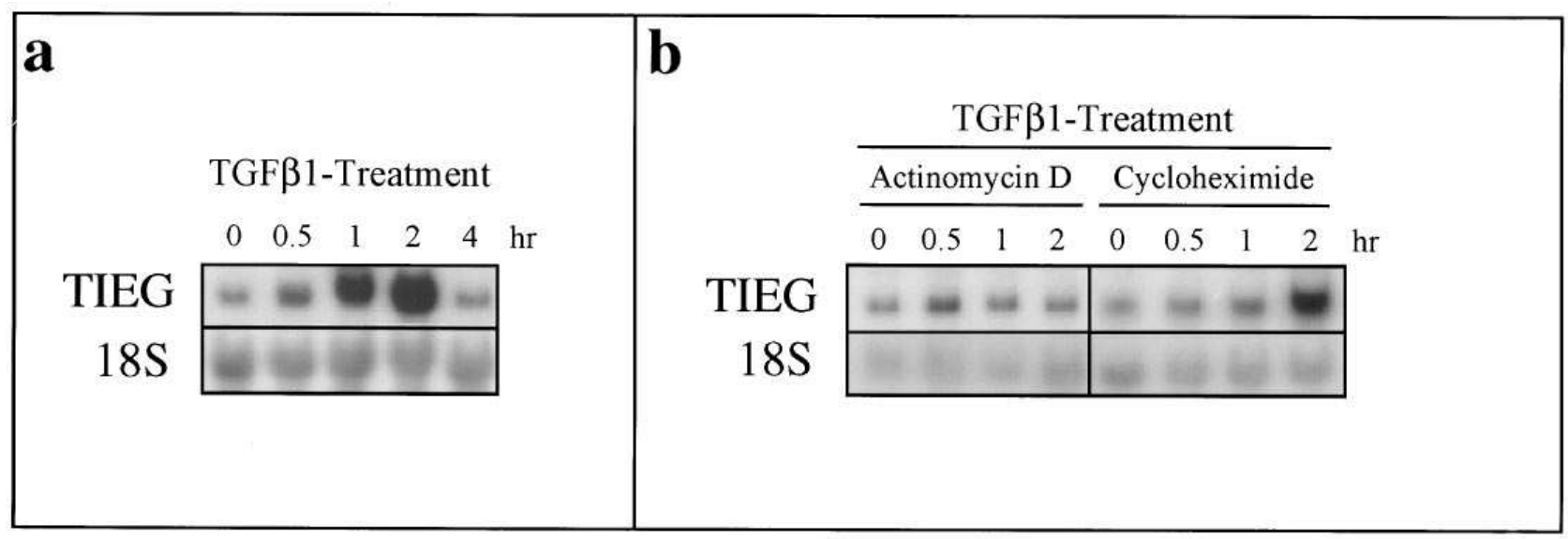

Figure 5. TIEG is an early response gene for TGF $\beta 1$ in pancreatic epithelial cell lines. (a) The temporal pattern of expression of TIEG in response to TGF $\beta 1$ treatment was determined in PANC1 cells by Northern blot analysis. PANC1 cells were treated with $5 \mathrm{ng} / \mathrm{ml}$ TGF 1 for $0.5,1$, 2 , and $4 \mathrm{~h}(0=$ untreated cells) before RNA extraction. Northern blot analysis was performed using $10 \mu \mathrm{g}$ total RNA. The TGF $\beta 1$-mediated upregulation in TIEG mRNA levels occurs as early as $2 \mathrm{~h}$ after treatment. (b) TIEG is an early response gene for TGF $\beta 1$ in pancreatic epithelial cell lines. PANC1 cells were treated with actinomycin D $(1 \mu \mathrm{g} / \mathrm{ml})$ or cycloheximide $(10 \mu \mathrm{g} / \mathrm{ml}) 30$ min before and during TGF $\beta 1$ stimulation, and Northern blot analysis was performed. The TGF $\beta 1$-mediated upregulation in TIEG mRNA levels occurs within $2 \mathrm{~h}$, even in the presence of the protein synthesis inhibitor cycloheximide, a defining feature of an early response gene. In contrast, treatment with the transcriptional inhibitor actinomycin D abolishes this upregulation of TIEG mRNA levels, indicating that the effects of this growth factor on TIEG expression occur at the level of transcription. 


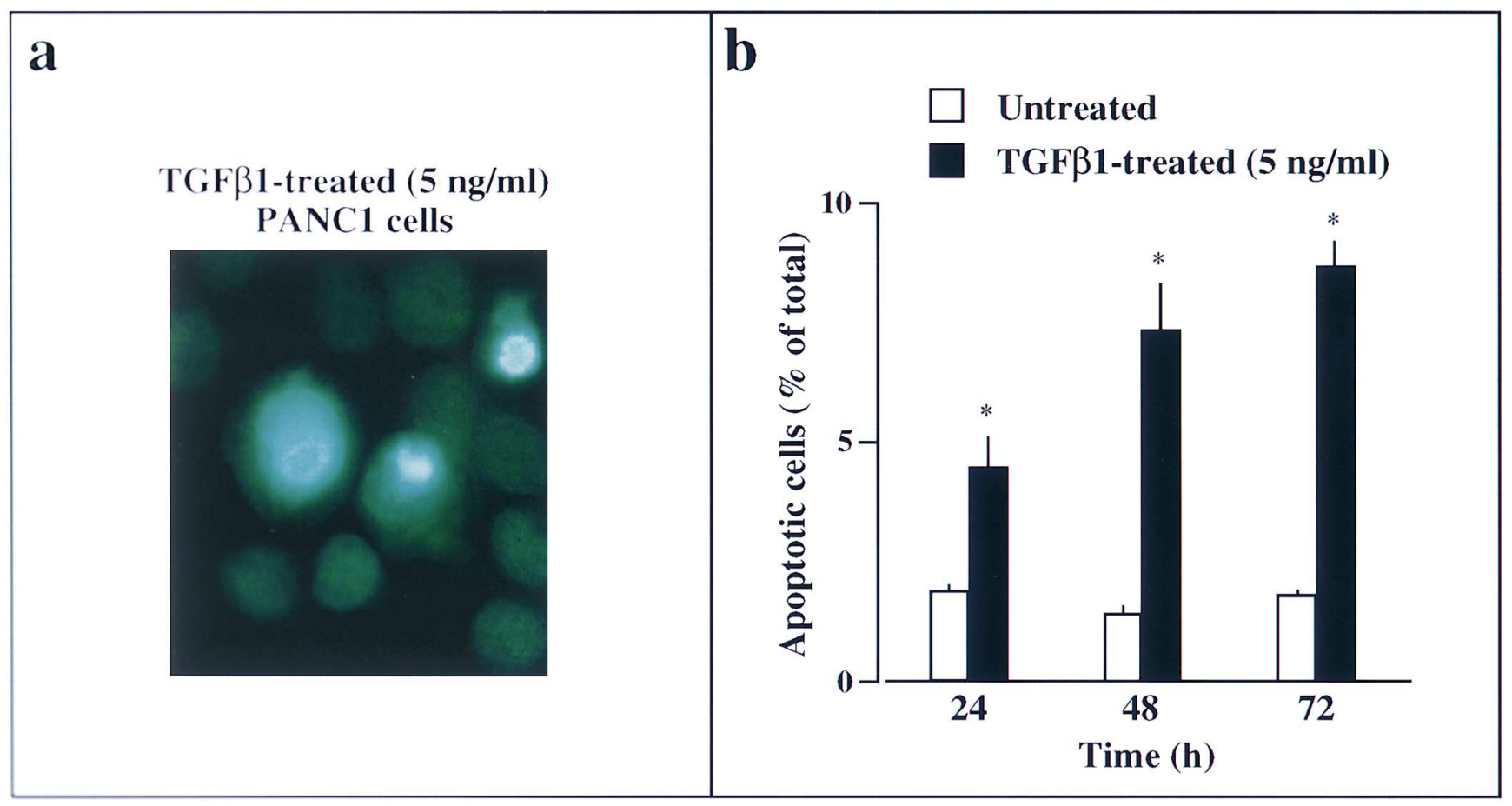

Figure 6. TGF 1 treatment increases the rate of apoptosis in PANC1 cells. PANC1 cells were treated with $5 \mathrm{ng} / \mathrm{ml} \mathrm{TGF} \beta 1$ for 24,48 , and $72 \mathrm{~h}$ and apoptosis was determined by analyzing the changes in chromatin condensation/margination and nuclear fragmentation using the fluorescent DNA-binding dye DAPI. An untreated PANC1 cell population was used as a control. (a) Typical morphological pattern compatible with apoptosis as determined by this assay. (b) Histogram showing the percentage of apoptotic cells in TGF 3 -treated PANC1 cells vs. control. At least 300 cells in four highpower fields were counted, and apoptotic cells were expressed as a percentage of total cells. Note that TGF 1 increases the rate of apoptosis determined at any time point, reaching an approximately fourfold increase from $2.6 \pm 0.6 \%$ to $8.8 \pm 0.5 \%$ after $72 \mathrm{~h}$.

of this growth factor on TIEG gene expression occur at the level of transcription.

Overexpression of TIEG in exocrine pancreatic cell lines induces apoptosis. Using transient transfection experiments, we overexpressed full length human TIEG in the exocrine pancreatic cell line PANC1 and measured the effect on cell proliferation. These cells have been previously described to be sensitive to the growth inhibitory effect of TGF $1(35,36)$ and are very useful for cell proliferation studies because they are highly transfectable using cationic liposomes $(72 \pm 4 \%$ as determined by $\beta$-galactosidase reporter assay). In addition, as shown in Fig. 6, TGF $\beta 1$ increases the rate of apoptosis fourfold in these cells as determined by a nuclear fragmentation assay (from $2.6 \pm 0.6 \%$ to $8.8 \pm 0.5 \%$ ). These values are comparable to the rates previously reported in hepatocytes (30), one of the most widely used models for studying TGF $\beta$-mediated programmed cell death, suggesting that PANC1 cells also provide a valuable model for studying this phenomenon. The results from the proliferation assay shown in Fig. 7 demonstrate that both untransfected PANC1 cells and cells transfected with the control vector (pMEX-neo) alone grow normally while cells transfected with pMEX-neo-TIEG stop proliferating. Note also that the number of cells in the group transfected with pMEXneo-TIEG is lower after $72 \mathrm{~h}$ than at the beginning of the experiment (Fig. 7 a). Moreover, although TIEG overexpression is detected at $24 \mathrm{~h}, 72 \mathrm{~h}$ after the beginning of the experiment, TIEG overexpression is no longer detectable in pMEX-neoTIEG-transfected cells (Fig. $7 b$ ). These results raised the possibility that TIEG induces apoptotic cell death rather than sim- ply arresting the cells in a specific phase of the cell cycle. To test this hypothesis, we determined whether these cells undergo apoptosis using nuclear fragmentation and DNA ladder assays. Indeed, Fig. $8 a$ shows that cells transfected with pMEX-neo-TIEG undergo apoptosis as evidenced by the classical morphological feature of chromatin margination/condensation and nuclear fragmentation. More than $30 \%$ of cells undergoing apoptosis can be detected in the TIEG-transfected cell population at any time point (Fig. $8 b$ ). This additively results in the net loss of cells observed using the MTS cell proliferation assay in Fig. $7 a$. Fig. $8 c$ shows the formation of a DNA ladder as a result of internucleosomal fragmentation. Thus, overexpression of TIEG is sufficient to induce apoptosis in exocrine pancreatic cell populations. To document this phenomenon at the cellular level, we determined the development of apoptosis in individually transfected cells using the TUNEL technique and fluorescence microscopy. For this purpose, we cotransfected the pMEX-neo-TIEG vector together with the pHook-2 lac Z plasmid (37) that encodes the HA epitope, thus allowing us to distinguish transfected from untransfected cells by immunofluorescence using an anti-HA antibody (33). A similar technique has also been previously used for separating cotransfected from untransfected cells using fluorescence activated cell sorting and the CD4 epitope (38). The results of these experiments, shown in Fig. $9 d$, demonstrate that transfected cells, as identified by the HA antibody, display both the morphological parameters of apoptosis under DIC (nuclear margination, cell shrinkage, and bleb formation) and the nuclear fragmentation as determined by the TUNEL technique. 


\section{a}

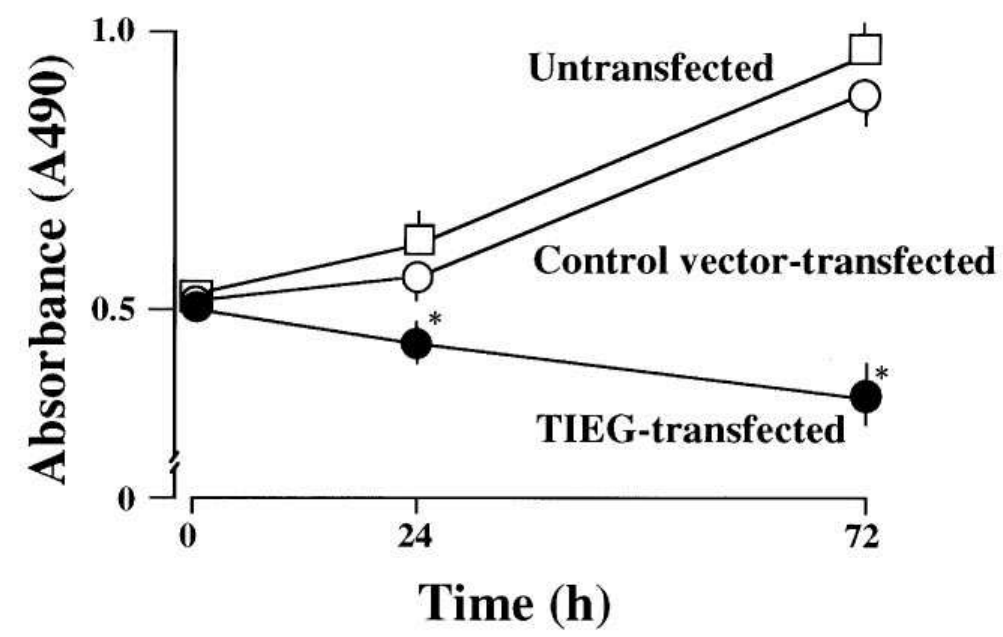

b

$\underline{\text { Transfected }}$ Transfected

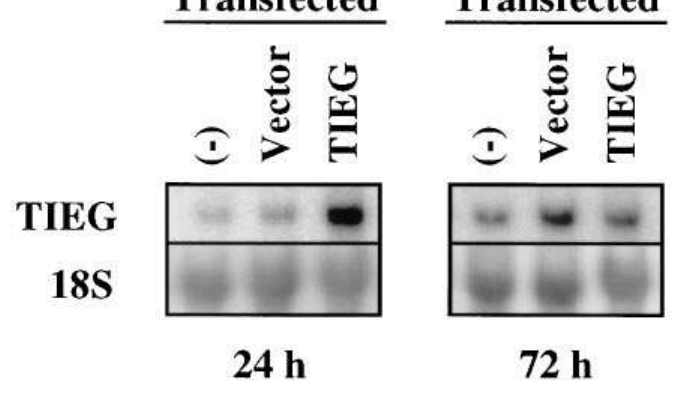

Figure 7. Overexpression of TIEG in pancreatic epithelial cells exert a negative effect on cell proliferation. (a) Proliferation assay of pancreatic epithelial cells transfected with TIEG. PANC1 cells were transfected with $10 \mu \mathrm{g}$ of the TIEG expression vector (pMEX-neo-TIEG) or the vector alone (pMEX-neo) using LipofectAMINE ${ }^{\mathrm{TM}}$. Proliferation was assayed using a colorimetric MTS assay. Note that TIEG overexpression significantly inhibits cell proliferation when compared with either untransfected cells or cells transfected with the control vector alone. Bars represent SEM. Statistical analyses were performed by ANOVA with the Fisher post hoc test using Statview 4.5 ${ }^{\mathrm{TM}}$ (Abacus Concepts, Inc., Berkeley, CA). *Significant difference $(P<0.05)$ in proliferation compared with untransfected cells and cells transfected with the vector alone. $(b)$ Overexpression of TIEG in transfected pancreatic epithelial cells as determined by Northern blot analysis. Northern blot analysis demonstrates that TIEG is overexpressed in PANC1 cells after $24 \mathrm{~h}$ of transfection with pMEX-neo-TIEG as compared with untransfected cells and cells transfected with the control plasmid alone (pMEX-neo). Note that TIEG overexpression is no longer detectable at $72 \mathrm{~h}$, suggesting that the number of TIEG-overexpressing cells was reduced due to apoptosis.

These features were absent in cells transfected with the control plasmid (data not shown). Therefore, these results further support the biochemical data presented above, demonstrating that cells transfected with TIEG undergo apoptosis.

\section{Discussion}

Continuing with our previous studies on the identification of transcription factors that participate in growth factor- and gastrointestinal hormone-regulated pancreatic cell growth (9-12), here we have characterized the expression and function of the TGF $\beta$-inducible zinc finger encoding gene TIEG in pancreatic epithelial cells. This gene was originally identified from a mesodermally derived osteoblastic cell population (21), but the cloning of the rat homologue from rat pancreas suggests a role for this transcription factor in epithelial-derived exocrine pancreatic cells as well. Using Western blot, immunohistochemistry, and Northern blot analyses, we have demonstrated that both the TIEG mRNA and protein are present in exocrine pancreatic cell populations and that TGF $\beta 1$ significantly upregulates the levels of TIEG even in the presence of cycloheximide, a defining feature of early response genes. Because early response genes have been proposed to be a direct link between growth factor signaling cascades and distinct cellular functions (39), these results led us to hypothesize that TIEG may mediate at least some of the negative effects of TGF $\beta$ on epithelial cell proliferation. Indeed, we have demonstrated that overexpression of TIEG in PANC1 cells stops cell proliferation and causes apoptosis. The rate of apoptosis detected in PANC1 cells transfected with TIEG is higher than the rate of 


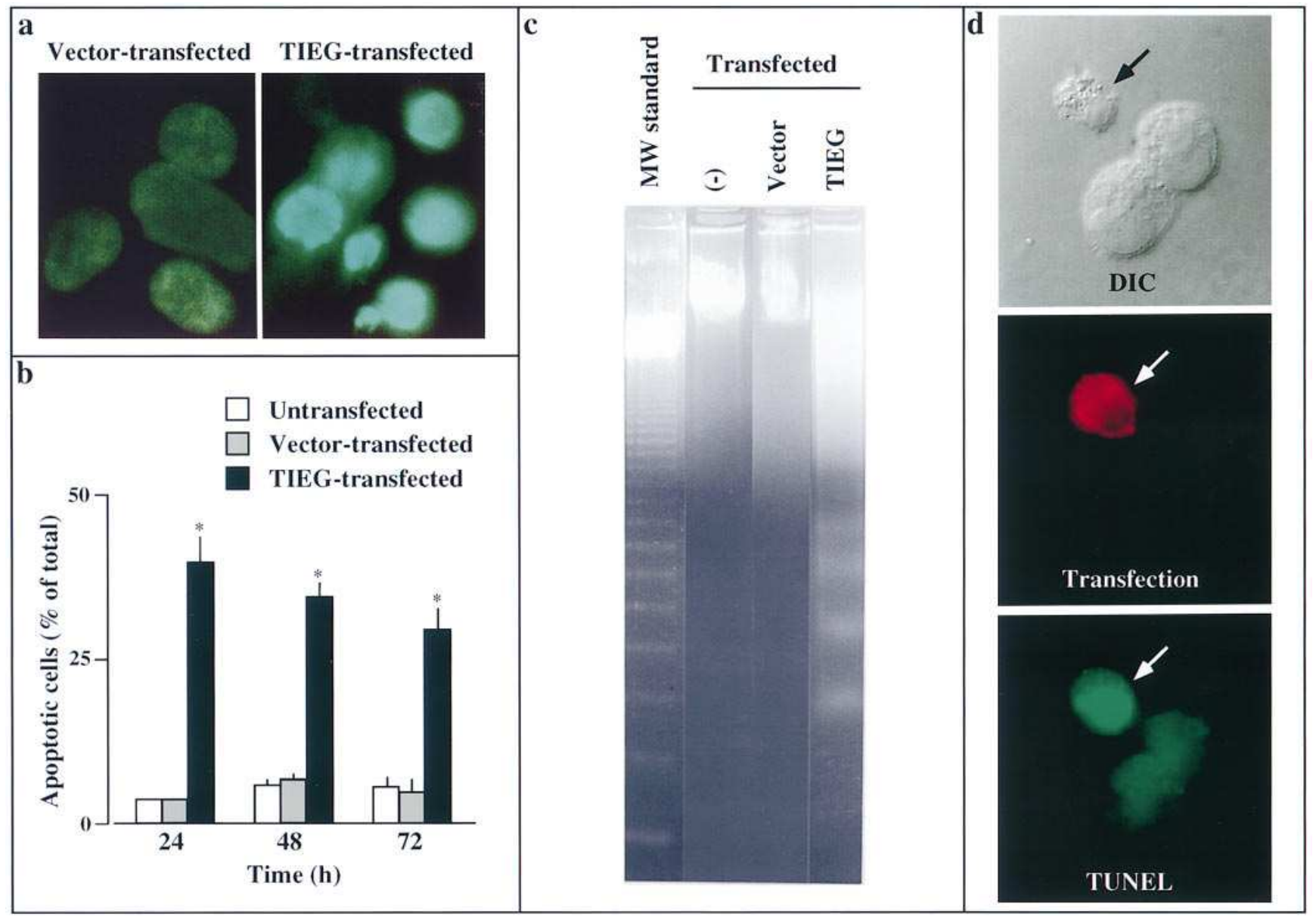

Figure 8. Overexpression of TIEG induces apoptosis in PANC1 cells. (a) PANC1 cells were transfected with pMEX-neo-TIEG or the control plasmid alone (pMEX-neo) and apoptosis was determined by analyzing the changes in chromatin condensation/margination and nuclear fragmentation using the fluorescent DNA binding dye DAPI. Note that TIEG-transfected cells undergo nuclear fragmentation events that are characteristic of apoptosis. These changes are not observed in cells transfected with the control vector alone (pMEX-neo). (b) Histogram showing the percentage of apoptotic cells in TIEG-transfected PANC1 cells as determined by the nuclear fragmentation assay described in $a$. At least 300 cells in four high power fields were counted, and apoptotic cells were expressed as a percentage of total cells. Note that $>30 \%$ of cells undergoing apoptosis can be detected in the TIEG-transfected cell population at any time point, which cumulatively results in the remarkable reduction in the cell number observed at the 72-h point using the MTS proliferation assay (Fig. 5). Bars represent mean \pm SEM. Statistical analyses were performed by ANOVA with the Fisher post hoc test using Statview $4.5^{\mathrm{TM}}$. *Significant difference $(P<0.05)$ compared with untransfected cells and cells transfected with the control vector alone (pMEX-neo) at each corresponding time point. (c) Apoptosis in TIEG-transfected PANC1 cells as determined using a DNA ladder assay. The formation of a DNA ladder resulting from the internucleosomal DNA fragmentation due to apoptosis was determined by agarose gel electrophoresis. DNA extracted from untransfected PANC1 cells or cells transfected with either TIEG (pMEX-neo-TIEG) or the control vector alone (pMEX-neo) was separated on a $2 \%$ agarose gel and stained with ethidium bromide. Note that cells transfected with TIEG undergo apoptosis as evidenced by the formation of the characteristic DNA ladder. Each of the bands observed in the DNA molecular weight $(M W)$ standard correspond to $123 \mathrm{bp}$. This laddering is not detected in untransfected cells and cells transfected with the control vector alone (pMEX-neo). (d) Apoptosis in individual TIEG-transfected PANC1 cells as determined using differential interference contrast microscopy $(D I C)$ and the TUNEL technique. PANC1 cells were cotransfected with the pMEX-neo-TIEG and the HA epitopeexpressing vector $\mathrm{pHook} 2$ lacZ. Individual transfected cells were identified by immunofluorescence using a primary anti-HA antibody and a rhodamine-labeled secondary antibody. Apoptosis was determined by both the morphological apoptotic parameters visualized under DIC and the in situ DNA fragmentation assay TUNEL using FITC-labeled dUTP. Note that the transfected cells that are positive for anti-HA staining (red) display the morphological landmarks of apoptosis such as nuclear margination, chromatin condensation, and cytoplasmic disorganization under DIC. These cells also display DNA fragmentation as visualized by the TUNEL technique (green). These signs were not observed in cells transfected with the control plasmid pMEX-neo.

cell death observed in these cells after TGF $\beta 1$ treatment. However, it is important to consider that the upregulation of TIEG observed after TGF $\beta 1$ treatment of PANC1 cells is transient, while the levels of TIEG expression obtained by transfection are expected to be maintained constantly high. Therefore, this experimental paradigm is expected to unmask the function of TIEG that otherwise would remain unclear. Similar approaches have previously been used to characterize the function of other key molecular regulators of apoptosis $(40,41)$. Therefore, TIEG is a bona fide candidate to mediate the apoptotic effects of TGF $\beta$ peptides in pancreatic epithelial cell populations. 
The involvement of TIEG in apoptosis as described here should be considered in light of the known effects of TGFB peptides in different cell populations, including pancreatic cells. While these growth factors induce proliferation in mesodermally derived cells, they are potent antiproliferative agents in most epithelial cells $(22,42)$. Moreover, in some cell types, growth arrest is accompanied by apoptotic cell death $(43,44)$. The best characterized among these TGF $\beta$-responsive epithelial cell populations are those of the gastrointestinal tract, liver, and pancreas. In these cell populations, TGF $\beta$ has been consistently shown to cause cell cycle arrest and also to induce apoptosis. However, the molecular machinery that participates in these growth inhibitory cascades is poorly characterized. Although it is known that TGF $\beta$ peptides activate heterodimeric receptors that display serine/threonine kinase activity, until very recently the cytoplasmic and nuclear proteins that participate in TGF $\beta$ signaling were almost unknown. Several reports have now identified a family of proteins known as MADs (Mothers against decapentaplegic), which act as transducers of TGF $\beta$ signaling from insects to vertebrates (45-47). The discovery of TIEG from osteoblasts as a TGF $\beta$-inducible early gene (21), together with these reports, identifies this zinc finger protein as an important player in this signaling cascade as well. However, a paradox still exists since, as stated above, TIEG is present not only in pancreatic epithelium where TGF $\beta$ inhibits cell growth, but also in mesodermally derived osteoblasts that proliferate in response to this peptide (48). It is therefore possible that TIEG induces cell proliferation in mesodermally derived cells. However, further studies are needed to answer this question.

In light of the results reported in this study, it becomes important to consider the potential participation of TIEG in TGF $\beta$-mediated signaling cascades that regulate cell growth not only during embryogenesis but also during the development of pancreatic diseases (5-14). As stated earlier, both chronic pancreatitis and pancreatic cancer are often accompanied by alterations in these signaling cascades. For instance, high levels of TGF $\beta$ peptides have been implicated in the development of fibrosis in both diseases, and probably contribute to the epithelial atrophy found in chronic pancreatitis (5-14). In addition, a recently identified candidate tumor suppressor gene for pancreatic cancer, DPC4, has been shown to belong to a family of proteins involved in TGF $\beta$-mediated signaling from insects to vertebrates $(14,45-47)$. Because of the antiproliferative effects of TGF $\beta$ peptides on epithelial pancreatic cells and the potential participation of DPC4 in these phenomena, alterations in this gene are expected to result in uncontrolled cell proliferation and perhaps neoplastic transformation (14). However, the defined cellular function of DPC4 has not yet been investigated and we do not know whether this protein functions upstream or downstream of TIEG in TGF $\beta$ signaling pathways. It also remains to be established whether mutations or altered expression of TIEG can result in neoplastic transformation. In this regard, based upon the negative effects of TIEG on epithelial pancreatic cell growth reported here, it becomes interesting to speculate that alterations in the function of this protein may be found in chronic pancreatitis and pancreatic cancer. Ongoing experiments in our laboratory are aimed at determining the expression and function of TIEG during the development of these diseases in both human and whole animal models.

The sequence homology reported here between TIEG and members of the Sp1 family of transcription factors is also an important finding that may help to better define the function of this gene product in various cell populations. As documented in this study, the DNA binding motifs within all of these proteins are highly homologous, suggesting that they may recognize the same or similar cis regulatory sequences. In this respect, Sp1-like sites have been demonstrated to be essential for the regulation of the gene products for the cell cycle inhibitors $\mathrm{p} 15$ and $\mathrm{p} 21$ by TGF $3(49,50)$. Recent investigations of TGF $\beta$-induced growth arrest indicate that it is mediated in part by $\mathrm{p} 21$ and p15 (49-51). Because of the TGF $\beta$ regulation and the negative effects of TIEG on epithelial cell proliferation, it is tempting to speculate that this protein may regulate the expression of p15 and p21 through binding to the Sp1-sites present in their promoters. Consequently, this upregulation of either p15 or p21 would inhibit cell cycle progression and stop cell proliferation. Further studies that focus on testing the validity of this model may give further insights on the molecular mechanisms underlying apoptotic cell death (52) in pancreatic epithelial cells.

In conclusion, we have demonstrated for the first time that the zinc finger encoding gene TIEG is expressed in pancreatic epithelial cell populations in a TGF $\beta$-inducible manner and that overexpression of TIEG in these cells results in apoptosis. Several studies indicate that TGF $\beta$-induced cell growth arrest and apoptosis are necessary to maintain the appropriate number of epithelial cell populations during pancreatic morphogenesis, regeneration, and the early stages of pancreatic carcinogenesis $(5-14,35,36)$. Thus, the results reported here identify TIEG as a good candidate to mediate these negative effects of TGF $\beta$ on pancreatic epithelial cell growth, expanding our understanding of the molecular machinery involved in this phenomenon.

\section{Acknowledgments}

We are grateful to Tiffany Cook, Karen Hedin, and Brian Gebelein for critically reading the manuscript.

This work was supported by the Mayo Foundation and National Institutes of Health grants AR-43627 to T.C. Spelsberg and DK-41876 to G.J. Gores.

\section{References}

1. Guan, K.L. 1994. The mitogen activated protein kinase signal transduction pathway: from the cell surface to the nucleus. Cell. Signalling. 6:581-589.

2. Hill, C.S., and R. Treisman. 1995. Transcriptional regulation by extracellular signals: mechanisms and specificity. Cell. 80:199-211.

3. Ruddon, R.W. 1995. Cell-cycle regulation and apoptosis. In Cancer Biology. Oxford University Press, New York. 386-401.

4. Raijman, I., and B. Levin. 1993. Exocrine tumors of the pancreas. In The Pancreas; Biology, Pathology, and Disease. V.L.W. Go, E.P. DiMagno, J.D. Gardner, E. Lebenthal, H.A. Reber, G.A. Scheele, editors. Raven Press, New York. 899-912.

5. Savito, F., P.L. Herrera, J. Huarte, A. Nichols, R. Montesano, L. Orci, and J.D. Vassalli. 1994. TGF $\beta 1$ influences the relative development of the exocrine and endocrine pancreas in vitro. Development (Camb.). 120:3451-3462.

6. Sarner, M. 1993. Pancreatitis definitions and classifications. In The Pancreas; Biology, Pathology, and Disease. V.L.W. Go, E.P. DiMagno, J.D. Gardner, E. Lebenthal, H.A. Reber, G.A. Scheele, editors. Raven Press, New York. $575-580$.

7. Sanvito, F., A. Nichols, P.L. Herrera, J. Huarte, A. Wohlwend, J.D. Vassalli, and L. Orci. 1995. TGF-beta 1 overexpression in murine pancreas induces chronic pancreatitis and, together with TNF-alpha, triggers insulin-dependent diabetes. Biochem. Biophys. Res. Commun. 217:1279-1286.

8. Slater, S.D., R.C. Williamson, and C.S. Foster. 1995. Expression of transforming growth factor beta 1 in chronic pancreatitis. Digestion. 56:237-241.

9. Lee, M.S, D. Gu, L. Feng, S. Curriden, M. Arnush, T. Krahl, D. Gurush- 
anthaiah, C. Wilson, D.L. Loskutoff, H. Fox, et al. 1995. Accumulation of extracellular matrix and developmental dysregulation in the pancreas by transgenic production of transforming growth factor-beta 1. Am. J Pathol. 147:42-52.

10. van Laethem, JL., J. Deviere, A. Resibois, F. Rickaert, P. Vertongen, H. Ohtani, M. Cremer, K. Miyazono, and P. Robberecht. 1995. Localization of transforming growth factor beta 1 and its latent binding protein in human chronic pancreatitis. Gastroenterology. 108:1873-1881.

11. Gress, T., F. Muller-Pillasch, H.P. Elsasser, M. Bachem, C. Ferrara, H. Weidenbach, M. Lerch, and G. Adler. 1994. Enhancement of transforming growth factor beta 1 expression in the rat pancreas during regeneration from caerulein-induced pancreatitis. Eur. J. Clin. Invest . 24:679-685.

12. Friess, H., Y. Yamanaka, M. Buchler, M. Ebert, H.G. Berger, L.I. Gold, and M. Korc. 1993. Enhanced expression of transforming growth factor beta isoforms in pancreatic cancer correlates with decreased survival. Gastroenterology. 105:1846-1856.

13. Friess, H., Y. Yamanaka, M. Buchler, H.G. Berger, M.S. Kobrin, R.L. Baldwin, and M. Korc. 1993. Enhanced expression of the type II transforming growth factor beta receptor in human pancreatic cancer cells without alteration of type III receptor expression. Cancer Res. 53:2704-2707.

14. Hahn, S.A., M. Schutte, A.T.M.S. Hoque, C.A. Moskaluk, L.T. da Costa, E. Rozenblum, C.L. Weinstein, A. Fischer, C.J. Yeo, R.H. Hruban, and S.E. Kern. 1996. DPC-4, a candidate tumor suppressor gene at human chromosome 18q21.1. Science (Wash. DC). 271:350-353.

15. Mesa, K., B. Gebelein, T. Cook, and R. Urrutia. 1996. Identification and characterization of zinc finger encoding genes from the tumoral exocrine pancreatic cell line AR42J. Cancer Lett. 103:143-149.

16. Gebelein, B., K. Mesa, and R. Urrutia. 1996. A novel profile of expressed sequence tags for zinc finger encoding genes from the poorly differentiated exocrine pancreatic cell line AR4IP. Cancer Lett. 105:225-231.

17. Mesa, K., B. Gebelein, and R. Urrutia. 1996. A novel krüppel-like zinc finger encoding gene isolated from pancreas is regulated by cholecystokinin. Pancreas. 13:500a. (Abstr.)

18. Gebelein, B., K. Mesa, M. Imoto, and R. Urrutia. 1996. Characterization of MAZF: a Mitogen-Activated Zinc Finger gene encoding a novel member of the krüppel-associated box subfamily of transcriptional repressor proteins. Pancreas. 13:438a. (Abstr.)

19. Kreidberg, J.A., H. Sariola, J.M. Loring, M. Maeda, J. Pelletier, D. Housman, and R. Jaenisch. 1993. WT-1 is required for early kidney development. Cell. 74:679-691.

20. Miyagawa, K., J. Kent, A. Schedl, V. van Heyningen, and N.D. Hastie. 1994. Wilms' tumor-a case of disrupted development. J. Cell. Sci. 18:(Suppl.):1-5.

21. Subramaniam, M., S.A. Harris, M.J. Oursler, K. Rasmussen, B.L. Riggs, and T.C. Spelsberg. 1995. Identification of a novel TGF $\beta$-regulated gene encoding a putative zinc finger protein in human osteoblasts. Nucleic Acids. Res. 23: 4907-4912.

22. Yingling, J.M., X.F. Wang, and C.H. Bassing. 1995. Signalling by the transforming growth factor- $\beta$ receptors. Biochem. Biophys. Acta. 1242:115-136.

23. Cook, T., K. Mesa, and R. Urrutia. 1996. Three dynamin-encoding genes are differentially expressed in the developing rat brain. J. Neurochem. 67: 927-931.

24. Chomczynski, P., and N. Sacchi. 1987. Single-step method of RNA isolation by acid guanidinium thiocyanate-phenol-chloroform extraction. Anal. Biochem. 162:156-159.

25. Laemmli, U.K. 1970. Cleavage of structural proteins during the assembly of the head of bacteriophage T4. Nature (Lond.). 227:680-685.

26. Towbin, H., T. Staehelin, and J. Gordon. 1979. Electrophoretic transfer of proteins from polyacrylamide gels to nitrocellulose sheets: procedure and some applications. Proc. Natl. Acad. Sci. USA. 76:4350-4354.

27. Cook, T.A., K.J. Mesa, B.A. Gebelein, and R. Urrutia. 1996. Up-regulation of dynamin II expression during the acquisition of a mature pancreatic acinar phenotype. J. Histochem. Cytochem. 44:1373-1378.

28. Huet, C. 1994. Production of polyclonal antibodies in rabbits. In Cell Biology: A Laboratory Handbook. J.E. Celis, editor. Academic Press, San Diego, CA. 257-268.

29. Huet, C. 1994. Purification of immunoglobulins. In Cell Biology: A Laboratory Handbook. J.E. Celis, editor. Academic Press, San Diego, CA. 291-296.

30. Oberhammer, F.A., M. Pavelka, S. Sharma, R. Tiefenbacher, A.F. Rurchio, W. Bursch, and R. Schulte-Hermann. 1992. Induction of apoptosis in cultured hepatocytes and in regressing liver by transforming growth factor beta 1. Proc. Natl. Acad. Sci. USA. 89:5408-5412.
31. Patel, T., S.F. Bronk, and G.J. Gores. 1994. Increase of intracellular magnesium promotes glycodeoxycholate-induced apoptosis in rat hepatocytes. J. Clin. Invest. 94:2183-2192.

32. Kwo, P., T. Patel, S.F. Bronk, and G.J. Gores. 1995. Nuclear serine protease activity contributes to bile acid-induced apoptosis in hepatocytes. Am. J. Physiol. 268:G613-G621.

33. Chen, Y.T, C. Holcomb, and H.P. Moore. 1993. Expression and localization of two low molecular weight GTP-binding proteins, Rab8 and Rab10, by epitope tag. Proc. Natl. Acad. Sci. USA. 90:6508-6512.

34. Urrutia, R., M.A. McNiven, J.P. Albanesi, D.B. Murphy, and B. Kachar. 1991. Purified kinesin promotes vesicle motility and induces active sliding between microtubules in vitro. Proc. Natl. Acad. Sci. USA. 88:6701-6705.

35. Baldwin, R.L., and M. Korc. 1993. Growth inhibition of human pancreatic carcinoma cells by transforming growth factor beta-1. Growth Factors. 8: 23-34.

36. Freeman, J.W., C.A. Mattingly, and W.E. Strodel. 1995. Increased tumorigenicity in the human pancreatic cell line MIAPaCa-2 is associated with an aberrant regulation of an IGF-1 autocrine loop and lack of expression of the TGF-beta type II receptor. J. Cell Physiol. 165:155-163.

37. Chesnut, J.D., A.R. Baytan, M. Russell, M.P. Chang, A. Bernard, and I.H. Maxwell 1996. Selective isolation of transiently transfected cells from a mammalian cell population with vectors expressing a membrane anchored single-chain antibody. J. Immunol. Methods. 193:17-27.

38. Krapivinsky, G., E.A. Gordon, K. Wickman, B. Velimirovic, L. Krapivinsky, and D.E. Clapham. 1995. The G-protein-gated atrial K+ channel IKACh is a heteromultimer of inwardly rectifying $\mathrm{K}(+)$-channel proteins. Nature. (Lond). 374:135-141.

39. Gashler, A., and V.P. Sukhatme. 1995. Early growth response protein 1 (Egr-1): prototype of a zinc finger family of transcription factors. Prog. Nucleic Acid Res. 50:191-224.

40. Meisenholder, G.W., S.J. Martin, D.R. Green., J. Nordberg, and B.M. Babior. 1996. Events in apoptosis. Acidification is downstream of protease activation and BCL-2 protection. J. Biol. Chem. 271:16260-16262.

41. Chinnaiyan, A.M., K. O'Rourke, M. Tewari, and V.M. Dixit. 1995. FADD, a novel death domain-containing protein, interacts with the death domain of Fas and intitiates apoptosis. Cell. 81:505-512.

42. Sporn, M.B., and A.B. Robberts. 1992. Transforming growth factor- $\beta$ : recent progress and new challenges. J. Cell Biol. 119:1017-1021.

43. Martikainen, P., N. Kyprianou, and J.T. Isaacs. 1990. Effect of transforming growth factor- $\beta 1$ on proliferation and death of rat prostatic cells. Endocrinology. 127:2963-2968.

44. Rotello, R.J., R.C. Lieberman, A.F. Purchio, and L.E. Gerschenson. 1991. Coordinated regulation of apoptosis and cell proliferation by transforming growth factor $\beta 1$ in cultured uterine epithelial cells. Proc. Natl. Acad. Sci. USA. 88:3412-3415.

45. Sekelsky, J.J., S.J. Newfeld, L.A. Raftery, E.H. Chartoff, W.M. Gelbart. 1995. Genetic characterization and cloning of mothers against dpp, a gene required for decapentaplegic function in Drosophila melanogaster. Genetics. 139: $1347-1358$.

46. Hoodless, P.A., T. Haerry, S. Abdollah, M. Stapleton, M.B. O'Connor, L. Attisano, and J.L. Wrana. 1996. MADR1, a MAD-related protein that functions in BMP2 signaling pathways. Cell. 85:489-500.

47. Zhang, Y., X. Feng, R. We, and R. Derynck. 1996. Receptor-associated MAD homologues synergize as effectors of the TGF-beta response. Nature (Lond). 383:168-172.

48. Centrella, M., T.L. McCarthy, and E. Canalis. 1991. Transforming growth factor-beta and remodeling of bone. J. Bone Jt. Surg. Am. Vol. 73:14181428 .

49. Li, J.M., M.A. Nichols, S. Chandrasekharan, Y. Xiong, and X.F. Wang. 1995. Transforming growth factor beta activates the promoter of cyclin-dependent kinase inhibitor $\mathrm{p} 15^{\mathrm{INK} 4 \mathrm{~B}}$ through an Sp1 consensus site. J. Biol. Chem. 270: 26750-26753.

50. Alexandrow, M.G., and H.L. Moses. 1995. Transforming growth factor $\beta 1$ and cell cycle regulation. Cancer Res. 55:1452-1457.

51. Datto, M.B., Y. Yu, and X.F. Wang. 1995. Functional analysis of the transforming growth factor beta responsive elements in the WAF1/Cip1/p21 promoter. J. Biol. Chem. 270:28623-28628.

52. McConkey, D.J., and S. Orrenius. 1994. Signal transduction pathways to apoptosis. Trends Cell Biol. 4:370-374. 